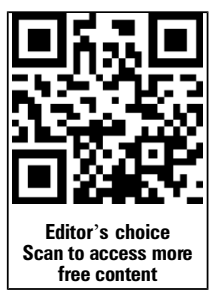

Correspondence to

Dr Patrick Fafard, Graduate School of Public and International Affairs, University of Ottawa, Room 6030, FSS Building, 120 University Private, Ottawa, Ontario, Canada K1N 6N5;

pfafard@uottawa.ca

Received 30 June 2014 Accepted 31 January 2015 Published Online First 25 February 2015

\section{CrossMark}

To cite: Fafard P. J Epidemiol Community Health 2015:69:1129-1132.

\title{
Beyond the usual suspects: using political science to enhance public health policy making
}

\author{
Patrick Fafard
}

\section{ABSTRACT}

That public health policy and practice should be evidence based is a seemingly uncontroversial claim. Yet governments and citizens routinely reject the best available evidence and prefer policies that reflect other considerations and concerns. The most common explanations of this paradox emphasise scientific disagreement, the power of 'politics', or the belief that scientists and policymakers live in two separate communities that do not communicate. However, another explanation may lie in the limits of the very notion of evidence-based policy making. In fact, the social science discipline of political science offers a rich body of theory and empirical evidence to explain the apparent gap between evidence and policy. This essay introduces this literature with a particular emphasis on a recent book by Katherine Smith, Beyond evidence-based policy in public health: the interplay of ideas. As the title suggests, Smith argues that what matters for public health policy is less scientific evidence and much more a more complex set of ideas. Based on detailed case studies of UK tobacco and health inequality policy, Smith offers a richly textured alternative account of what matters for policy making. This excellent book is part of a small but growing body of political science research on public health policy that draws on contemporary theories of policy change and governance more generally. This essay provides a window on this research, describes some examples, but emphasises that public health scholars and practitioners too often retain a narrow if not naive view of the policy-making process.

Evidence-based public health (EBPH), how could it be otherwise? The claim that practices, programmes and policies in public health should be based on the best available evidence seems like an obvious and self-evident claim. Yet we routinely observe that public health decisions are made that do not reflect the best available scientific evidence. How to explain this paradox? There are a number of standard explanations that typically emphasize better relationships. However, in this essay I will argue that a more compelling set of answers can be found in the work of political scientists and other social scientists who study the process by which public policy is made. A political science account challenges the assumed linkage between scientific evidence and public health policy. As Katherine Smith has argued: "the question becomes not, "why is public health policy not evidence-based?' but 'why would you ever assume it could (or even should) be?'” (ref. 1, p.4). To make the case for a political science perspective on public health policy this essay begins with a short overview of the movement for evidence-based decision-making in public health and some of the most popular explanations for the fact that, very often, aspirations for rationality are not realised. The second part is a sustained discussion of an important recent book that argues that to understand policy change in public health we are much better to focus, not on scientific evidence, but on ideas. The third part of the essay broadens the discussion to other work by political scientists on public health policy. The overall goal is to paint a picture of different ways of understanding the relationship between public health science and public health policy that reflect ongoing research on how public policy is made and the varying roles of scientific evidence in that process.

\section{EVIDENCE-BASED PUBLIC HEALTH}

At some basic level, evidence-based decisionmaking is a good thing. Even more so if the alternative is decisions based on habit, anecdote or outmoded training and education. Over the past decade or so, there has been a movement to strengthen EBPH decision-making. ${ }^{2}$ This movement is part of a larger and not unrelated emphasis on evidence-based medicine that began in the 1990s if not before. ${ }^{3}$ And in some countries, notably the UK, the interest in EBPH was almost certainly aided and abetted by the emphasis by the government of Prime Minister Tony Blair on evidence-based policy making. ${ }^{4}$ The emphasis on evidence by the Blair government, while most certainly uneven it its application sparked a considerable amount of ongoing research and reflection designed to better understand the role of evidence in policy making, including policy making in public health. $^{5}$

At the same time, a great deal of work has been done and is ongoing on how best to make evidence available to public health decisionmakers. There is an enormous amount of research being done on patterns of knowledge translation, knowledge transfer and knowledge mobilisation (the term of art varies by country, field and researcher). ${ }^{67}$ This movement has given rise to the emphasis on plain language summaries, knowledge brokers and closer partnerships between researchers and decisionmakers.

But this emphasis on EBPH quickly gives rise to a paradox. Notwithstanding the emphasis on evidence, there are regular claims that governments are making health-related decisions that ignore or at least downplay the best available science. Consider the following examples. It is generally agreed that increasing the numbers of people vaccinated against a given infectious disease will create so-called 'herd immunity' making the vaccination programme all that more effective. Yet in a number 
of communities in the USA and elsewhere there are widespread exemptions from 'mandatory' requirements for childhood immunisation for people who do not want their children to be immunised. ${ }^{8}$

In the UK, in the face of significant morbidity and mortality associated with alcohol abuse, the government refuses to institute minimum alcohol pricing even though there is strong evidence showing the price affects consumption among those who are inclined to abuse alcohol. ${ }^{9}$ In Canada the federal government threatened to close the country's only safe injection site despite the evidence that the facility saved lives. ${ }^{10}$ In a number of Organization for Economic Cooperation and Development countries local municipal councils have decided to stop water fluoridation despite a (but by no means universal) scientific consensus that the practice has a powerful impact on dental health with few if any associated risks to health. ${ }^{11}$ In each of these cases there would appear to have been a disconnect between scientific evidence and public policy.

Why? Why do governments make decisions that, on the face of it, do not appear to reflect the best available scientific evidence? One straightforward answer is that the scientific evidence that might inform a policy decision is itself contested. Sometimes this scientific disagreement is the result of manipulation by powerful actors. ${ }^{12}$ In many cases, however, it is because there is, on the face of it, a genuine disagreement over what the science says. For example, notwithstanding the strong public health advice that reducing dietary sodium is critical in reducing the incidence of stroke, there is an ongoing, and at times rather harsh debate between experts in the field. ${ }^{13-15}$ Similarly, there are those who would challenge, on scientific grounds, the link between water fluoridation and the reduced incidence of dental cavities among children. ${ }^{16}$

Another popular answer is that 'politics' or 'ideology' crowds out evidence. On this view, the alternative to evidence-based decision-making in public health, or anywhere else for that matter, is one where decisions are made on the basis of the political or ideological convictions of the government of the day. ${ }^{17-19}$ This was a common concern raised about decision-making by the government of George W Bush and indeed is a common explanation for decision-making by right-of-centre governments that, on the face of it, do not reflect the best available science. ${ }^{20} 21$ This is also a common explanation for the position taken by centre-left groups who reject the scientific consensus on the safety of such things as vaccinations or fluoridated water.

\section{CHALLENGING THE EVIDENCE-BASED PREMISE}

There is, however, an alternative answer to the question of why evidence-based policy is so elusive. The fact that governments sometimes make decisions that are at best inconsistent with the best available scientific evidence might be explained by the fact that the whole notion of evidence-based policy making is often based on a linear, direct, causal relationship between evidence and policy. ${ }^{22}$ There is, and arguably should be, some sort of a relationship between scientific evidence and public health decision-making. However, it is less obvious that the link is, can be (or even should be), a direct one. In other words, just as critiques of evidence-based medicine have tried to suggest a more complex relationship between evidence and clinical practice, ${ }^{23}$ there is a similarly complex relationship in public health. To better understand this complexity, there is a small but growing trend to try and understand some of the big policy decisions in public health using the tools and insights of political science and policy studies. This is because theories of policy change from political science offer a more nuanced account of the policy- making process and offer a more sophisticated account of the role that evidence does and does not play in policy making.

One excellent example of this is a recent book by Katherine E Smith, Beyond evidence-based policy in public health: the interplay of ideas. ${ }^{1}$ The book begins with a useful introduction to the rise of evidence-based policy and provides an overview of the strengths and weaknesses of the various ways of understanding the relationships between research and policy. Early on Smith offers an overview of the 'fluctuating fortunes' of the theory and practice of evidence-based policy. In doing so, she provides a provocative critique of the oft-repeated 'twocommunities' conception of the relationship between those who produce evidence and those who ostensibly are expected to use it to make decisions. On this account the challenge is to overcome institutional and cultural 'gaps' between 'researchers' and 'policymakers'. The preferred response is a varying mix of knowledge translation practices which will be familiar to anyone interested in the relationship between evidence and policy (eg, provide clear, concise summaries, develop collaborative relationships, etc). Smith shrewdly observes that this definition of the problem and the preferred solutions assumes, among other things, that researchers are able to directly respond to the questions and concerns of policymakers. It is also assumed that both sides share a common conception of, not just the implications of research findings but the issues that are worthy of research attention. She also pointedly asks whether greater use of research in policy making is always a good thing given what we now know about how scientific research is shaped by powerful economic interests. And for those looking for a more systematic account of the role of evidence in policy making, the last part of the first chapter offers a succinct and pithy overview of some of the different political science theories of policy making and policy change and how each understands the role of research evidence. This summary shows how far political science has moved beyond a simple linear, causal model of the relationship between research and policy.

The overall argument of the book is grounded in two case studies-health inequalities and tobacco control-to illustrate the difficulty in actually doing EBPH policy. Smith uses these cases to make a more general argument. She seeks to demonstrate public policy is driven less by scientific evidence and much more by research-based ideas. To do so, she surveys the political science literature on the role of ideas in policy making and then draws on an extensive body of qualitative evidence (ie, 141 interviews and an extensive analysis of documents) to look more closely at the role of ideas and evidence for each of the two case studies. In the case of health inequality, Smith argues that there are six different journeys from ideas to policy ranging from successful through recontextualised, partial, fractured and weak, to non-journeys where research-informed ideas do not appear to have travelled into policy at all (chapter 3 ). In the case of tobacco, as others have done, ${ }^{24}$ she argues that, rather than a simple evidence model, policy change is best explained with reference to advocacy coalitions and, more specifically, how the tobacco control coalition successfully deployed a series of policy frames which helped expand support for specific policy and programme initiatives. In doing so, however, she makes the perceptive and provocative point that on a number of occasions tobacco control measures were introduced before the research evidence was available. Note that a similar pattern can be found in other areas of public health notably harm reduction and illegal drugs. ${ }^{25}{ }^{26}$ Having made the case for the primacy of ideas (rather than evidence), the three subsequent chapters develop a second core argument of the book namely that the 
relationship between research and policy is, following Rein, one of 'interplay' or, as Smith puts it a "continual exchange and translation of ideas" (ref. 1, p.75). She elaborates this to suggest that there are four types of ideas: (1) institutionalised, (2) critical, (3) charismatic, (4) chameleonic, institutionalised ideas which have become 'unchallengeable' and embedded in policy and discourse; critical and charismatic ideas, which in different ways may challenge the status quo and usurp institutionalised ideas; and chameleonic ideas, which can simultaneously appeal and be acceptable to a variety of policy actors but also challenge existing policy.

\section{PUBLIC HEALTH MEET POLITICAL SCIENCE}

Smith's excellent book is part of a larger body of literature that seeks to apply the insights of political science to public health policy making. There is a large political science literature that seeks to understand the process by which public policy is made and to explain policy change be it major or, what is more likely, incremental. ${ }^{27} \mathrm{~A}$ small number of political scientists and public health specialists have begun to use this body of theory and research to better understand public health policy. A comprehensive survey is beyond the scope of this essay but useful overviews are available elsewhere. ${ }^{128-30}$ However, a few examples will demonstrate the trend.

A prominent theory of policy change is the advocacy coalition framework (ACF) first developed by Sabatier and extended and modified since. ${ }^{31} 32$ So, for example, Eric Breton and his colleagues have used the ACF, a well-known approach to explaining policy change, to better understand tobacco policy in the Canadian province of Québec. ${ }^{21}$ Similarly, Exworthy uses the ACF and other models of policy making to offer an alternative account of how governments might develop policies and programmes to address the social determinants of health and the associated constraints and opportunities facing policymakers. ${ }^{33}$

Kingdon's multiple streams approach is another model of the policy-making process that is increasingly used to better understand a range of public health policies. To take but three examples, this approach has been used to better understand a range of municipal-level public health policies in Sweden, ${ }^{34}$ the implementation of health-in-all policies in South Australia, ${ }^{35}$ and the efforts to implement a housing first approach to homelessness in Canada. ${ }^{36}$ However, it is important to note that, in these cases as in others, ${ }^{37}{ }^{38}$ the authors selectively and partially deploy Kingdon's notion of a policy entrepreneur or the concept of a policy window, without necessarily embracing the other elements of the approach to explaining policy change. ${ }^{39}$

Other insights from political science and other social sciences have also been applied in public health. For example, the political scientists Donley Studlar and Paul Cairney have performed a considerable amount of research on tobacco control drawing very explicitly on theories of policy change. ${ }^{40-42}$ While middlelevel theories of policy change as developed by Kingdon, Sabatier and others are predominant in contemporary political science, there are other theories of policy making and politics more generally that offer a more critical if not radical perspective on policy making including for public health. So, for example, Dennis Raphael has drawn on work that emphasises social class and the power of the business and corporate sector to better understand the limited impact of our increased understanding of the social determinants of health and the importance of healthy public policy. ${ }^{30}{ }^{43}$ In a related vein, Carles Muntaner and others have written extensively on the implications of the different kinds of welfare states and different political parties for the basket of policies that states adopt and their concomitant implications for population and public health. ${ }^{44-46}$

However, it would be a mistake to overemphasise the extent to which the public health enterprise (or at least public health scholars) draw on the insights of political science. Systematic reviews reveal that there remains limited mutual learning between political science and public health. Based on their review, De Leeuw and Breton argue that the body of knowledge developed by political science "has still made little inroads into health promotion policy research" (ref. 25, p.87). Similarly, Oliver $e t a l^{47}$ reported that when considering the use of evidence by policymakers few health policy studies provide clear definitions of policy, policymaker or evidence. Bernier and Clavier conclude that public health researchers "still have a naïve, idealistic and narrow view of public policy that is detrimental to understanding public policy as a determinant of health" (ref. 26, p.110).

As an infamous political theorist and revolutionary once asked, what is to be done? How can students of public health policy deploy a more nuanced conception of the role that scientific evidence does, and does not, play in the development of public health policy? As should be clear by now, my main suggestion is that the public health community should systematically engage with the insights of scholars in political science and policy studies. This can take the form of different kinds of research collaboration and training. However, this work is hard to do insofar as political scientists and public health scholars and professionals, while they may share an interest in public health policies as they are related to say, tobacco control or the regulation of dietary sodium, approach these issues in sometimes very different ways. Managing this creative tension requires imagination and flexibility on the part of research funders and public health managers. ${ }^{48}$ In effect, it requires public health to expand its reach beyond the cast of usual suspects.

\section{Key Messages}

- The conventional explanations for the supposed gap between public health evidence and policy are incomplete.

- In a powerful new book Katherine Smith argues that policy change in public health can better be explained with reference, not to evidence, but to broad ideas.

- More generally, political science offers a body of theory and evidence to explain the varying relationship between evidence and policy in public health.

\section{Competing interests None.}

\section{Patient consent Obtained.}

Provenance and peer review Commissioned; internally peer reviewed.

\section{REFERENCES}

1 Smith K. Beyond evidence-based policy in public health: the interplay of ideas. Houdmills, Basingstoke, Hampshire, UK: Palgrave Macmillan, 2013.

2 Brownson RC, Fielding JE, Maylahn CM. Evidence-based public health: a fundamental concept for public health practice. Annu Rev Public Health 2009;30:175-201

3 Claridge JA, Fabian TC. History and development of evidence-based medicine. World J Surg 2005;29:547-53.

4 Wells P. New labour and evidence based policy making: 1997-2007. People Place Policy Online 2007:22-9. 
5 Brownson RC, Baker EA, Leet TL, et al. Evidence-based public health. Oxford University Press, 2010:313p.

6 Straus S. Knowledge translation in health care: moving from evidence to practice. Hoboken, NJ: Wiley-Blackwell/BMJ, 2009.

7 Bennet A, Bennet D, Fafard K, et al. Knowledge mobilization in the social sciences and humanities. Frost, WV: MQI Press, 2007.

8 Omer SB, Salmon DA, Orenstein WA, et al. Vaccine refusal, mandatory immunization, and the risks of vaccine-preventable diseases. N Engl J Med 2009;360:1981-8.

9 Gilmore I, Daube M. How a minimum unit price for alcohol was scuppered. BMJ 2014;348:g23.

10 Boyd N. Lessons from INSITE, Vancouver's supervised injection facility: 2003-2012. Drugs (Abingdon Engl) 2013;20:234-40.

11 Pratt E Jr, Rawson RD, Rubin M. Fluoridation at fifty: what have we learned? J Law Med Ethics 2002;30(3 Suppl):117-21.

12 Oreskes N, Conway EM. Merchants of doubt. New York, NY: Bloomsbury US, 2010

13 Campbell NRC, Cappuccio FP, Tobe SW. Unnecessary controversy regarding dietary sodium: a lot about a little. Can J Cardiol 2011;27:404-6.

14 McCarron DA, Drüeke TB, Stricker EM. Science trumps politics: urinary sodium data challenge US dietary sodium guideline. Am J Clin Nutr 2010;92:1005-6.

15 Taubes $\mathrm{G}$. We only think we know the truth about salt. The New York Times 2 June 2012. http://www.nytimes.com/2012/06/03/opinion/sunday/ we-only-think-we-know-the-truth-about-salt.html (accessed 17 Jun 2014).

16 Peckham S. Slaying sacred cows: is it time to pull the plug on water fluoridation? Crit Public Health 2012;22:159-77.

17 Dodson EA, Stamatakis KA, Chalifour S, et al. State legislators' work on public health-related issues: what influences priorities? I Public Health Manag Pract 2013;19:25-9.

18 McKee M, Karanikolos M, Belcher $P$, et al. Austerity: a failed experiment on the people of Europe. Clin Med 2012;12:346-50.

19 Whitehead M, Dahlgren G, Mclntyre D. Putting equity center stage: challenging evidence-free reforms. Int J Health Serv 2007;37:353-61.

20 Leshner Al. Don't let ideology trump science. Science 2003;302:1479.

21 Hwang SW. Science and ideology. Open Med 2007;1:99-101.

22 Clavier C, De Leeuw E. Framing public policy in health promotion: ubiquitous, yet elusive. In: Clavier $C$, de Leeuw $E$, eds. Health promotion and the policy process. New York, NY: Oxford, 2013:1-22.

23 Greenhalgh T, Howick J, Maskrey N; for the Evidence Based Medicine Renaissance Group. Evidence based medicine: a movement in crisis? BMJ 2014;348:g3725.

24 Breton E, Richard L, Gagnon F, et al. Health promotion research and practice require sound policy analysis models: the case of Quebec's Tobacco Act. Soc Sci Med 2008;67:1679-89..

25 Dooling K, Rachlis M. Vancouver's supervised injection facility challenges Canada's drug laws. CMAJ 2010;182:1440-4.

26 Fafard P. Public health understandings of policy and power: lessons from INSITE. J Urban Health 2012;89:905-14.

27 Atkinson MM. Lindblom's lament: incrementalism and the persistent pull of the status quo. Policy Soc 2011;30:9-18.

28 Breton $\mathrm{E}$, De Leeuw $\mathrm{E}$. Theories of the policy process in health promotion research: a review. Health Promot Int 2011;26:82-90.
29 Bernier NF, Clavier C. Public health policy research: making the case for a political science approach. Health Promot Int 2011;26:109-16.

30 Sabatier $\mathrm{P}$, Jenkins-Smith $\mathrm{H}$. The advocacy coalition framework: an assessment. In: Sabatier PA, ed. Theories of the policy process. Boulder: Westview, 1999:117-68.

31 Weible CM, Sabatier PA, Jenkins-Smith HC, et al. A quarter century of the advocacy coalition framework: an introduction to the special issue. Policy Stud J 2011;39: 349-60.

32 Exworthy M. Policy to tackle the social determinants of health: using conceptual models to understand the policy process. Health Policy Plan 2008;23:318-27.

33 Guldbrandsson K, Fossum B. An exploration of the theoretical concepts policy windows and policy entrepreneurs at the Swedish public health arena. Health Promot Int 2009;24:434-44

34 Baum F, Lawless A, Williams C. Health in all policies from international ideas to local implementation: policies, systems, and organizations. In: Clavier C, De Leeuw $\mathrm{E}$, eds. Health promotion and the policy process. New York: Oxford, 2013:189-217.

35 Macnaughton E, Nelson G, Goering P. Bringing politics and evidence together: policy entrepreneurship and the conception of the At Home/Chez Soi Housing First Initiative for addressing homelessness and mental illness in Canada. Soc Sci Med 2013;82:100-7.

36 Gagnon ML, Labonté R. Understanding how and why health is integrated into foreign policy - a case study of health is global, a UK Government Strategy 20082013. Global Health 2013;9:24.

37 Nay 0. How do policy ideas spread among international administrations? Policy entrepreneurs and bureaucratic influence in the UN response to AIDS. J Public Policy 2012;32:53-76

38 Breton E, de Leeuw E. Multiple streams theory in Sweden: an error III. Health Promot Int 2010;25:134-5

39 Studlar DT. Tobacco control policy instruments in a shrinking world: how much policy learning? Int/ J Public Adm 2006;29:367-96.

40 Studlar DT. US tobacco control: public health, political economy, or morality policy? Rev Policy Res 2008;25:393-410.

41 Cairney P. The role of ideas in policy transfer: the case of UK smoking bans since devolution. J Eur Public Policy 2009;16:471-88.

42 Raphael D. The social determinants of non-communicable diseases: a political perspective. In: McQueen DV, ed. Global handbook on noncommunicable diseases and health promotion. New York: Springer, 2013:95-113.

43 Raphael D. Social determinants of health: present status, unanswered questions, and future directions. Int J Health Serv 2006;36:651-77.

44 Muntaner C, Borrell C, Ng E, et al. Politics, welfare regimes, and population health: controversies and evidence. Sociol Health IIIn 2011;33:946-64.

45 Navarro V, Muntaner C, Borrell C, et al. Politics and health outcomes. Lancet 2006;368:1033-7.

46 Mackenbach JP. Political determinants of health. Eur J Public Health 2014;24:2.

47 Oliver $\mathrm{K}$, Innvar $\mathrm{S}$, Lorenc $\mathrm{T}$, et al. A systematic review of barriers to and facilitators of the use of evidence by policymakers. BMC Health Serv Res 2014;14:2.

48 Cairney P. How can policy theory have an impact on policy making? The role of theory-led academic-practitioner discussions. Teach Public Adm. 2014;33:22-39. 